\title{
Health Benefits of Social Capital: A Multilevel Analysis of the Asian Barometer Survey (2003)
}

\author{
Harris Hyun-soo Kim ${ }^{1}$ \\ ${ }^{1}$ Department of Sociology, Ewha Womans University, Seoul, Republic of Korea \\ Correspondence: Harris Hyun-soo Kim, Department of Sociology, Ewha Womans University, 52 \\ Ewhayeodae-gil, Seodaemun-gu, Seoul, 120-750, Republic of Korea. Tel: 82-2-3277-4643. E-mail: \\ harrishkim@ewha.ac.kr
}

Received: April 22, 2013 Accepted: August 01, 2013 Online Published: September 29, 2013

doi:10.5539/ass.v9n13p63 URL: http://dx.doi.org/10.5539/ass.v9n13p63

\begin{abstract}
The purpose of this study is to examine the social determinants of health based on the analysis of the Asian Barometer Survey (2003) which consists of cross-national representative populations in ten Asian countries. The study investigates how and to what extent social capital- measured in terms of general trust, political trust, and social network is associated with self-rated health, while controlling for a host of socioeconomic and demographic variables. The results from the multilevel analysis reveal that all three social capital indicators have a consistent and robust effect across different models at the individual level. At the contextual (country) level, however, only the social network variable reaches the conventional level of statistical significance. The current research serves to fill an empirical gap in the extant literature which mostly contains studies on European and North American cases.
\end{abstract}

Keywords: social capital, social determinants of health, general trust, political trust, social network

\section{Introduction}

\subsection{Social Determinants of Health}

The relationship between social capital and health has been a focus of intense research in social epidemiology and medical sociology. Previous studies have shown that social factors play a significant role in promoting psychological and physical well-being of individuals. The original insight for the health benefits of social capital dates back to the classic writings of Emile Durkheim (1951), who demonstrated the role of the social environment in shaping one of the most quintessential individualistic acts: suicide. A substantial and growing body of multidisciplinary literature has emerged to demonstrate the link between social environmental factors and physical health, subjective well-being, and life satisfaction (for reviews, see, e.g., Berkman et al., 2000; Ferlander, 2007; Kawachi \& Berkman, 2000; Kawachi, Kim, Coutts \& Subramanian, 2004; Smith \& Christakis, 2008; Uchino, 2006).

The extant literature also relies heavily on the theoretical works by Bourdieu (1986), Coleman (1988), and Putnam (1993), who have explicitly theorized about "social capital," which is broadly defined as accessible resources embedded in social relations and structures. Many versions this concept have been put forth in the health research with both complementary and mixed empirical results, depending on how social capital is defined and measured. Despite some of the conceptual and methodological shortcomings, "social capital" has provided a great deal of analytical mileage in examining the complex relationship between various dimensions of health and different aspects of social environment (e.g., Barefoot, Gronbaek, Jensen, Schnohr \& Prescott, 2005; Cornwell \& Waite, 2009; Kumar, Calvo, Avendano, Sivaramakrishnan \& Berkman, 2012; Kim, Subramanian \& Kawachi, 2006; Mohnen, Groenewegen, Volker \& Flap, 2011; Moore, Bockenholt, Daniel, Frohlich, Kestens \& Richard, 2011; Yip, Subramanian, Mitchell, Lee, Wang \& Kawachi, 2007).

\subsection{Causal Mechanisms}

Four "primary pathways" in the literature are cited that purport to explain the processes by which social capital influences physical and psychological well-being. As articulated by Berkman et al. (2000, pp. 846), they include the provision of social support, social influence, social engagement and attachment, and access to resources and material goods. Some of the other key mechanisms have to do with the "faster diffusion of knowledge about 
health related innovations, maintenance of healthy norms, promotion of access to local services and amenities, and contributions to psychosocial processes that provide affective support and mutual respect" (Kim et al., 2006, pp. 116). There are other variations on this common theme often mentioned by social epidemiologists in their respective research (see e.g., Song \& Lin, 2009). The causal mechanisms are also seen to vary as a function of social capital form or type (e.g., "bonding" versus "bridging"), the level at which the concept is defined (individual or collective), and whether it is characterized in cognitive or structural terms (Silva, McKenzie, Harpham \& Huttly, 2005; Ferlander, 2007; Kawachi et al., 2004).

\subsection{Empirical Gap}

While there is indeed a substantial literature on the health benefits of social capital, the bulk of the previous research has dealt primarily with developed nations (Habibov \& Afandi, 2011; Kumar et al., 2012; Mansyur, Amick, Harrist \& Franzini, 2008; Sapag, Aracena, Villarroel, Poblete, Berrocal, Hoyos, Martinez \& Kawachi, 2008; Yip et al., 2007). In a recent article based on the large Gallop World Poll dataset covering 139 countries, Kumar et al. (2012) observe that the reputed link between "social capital and health in non-Western countries is a yet a matter of debate" (pp. 697). This empirical gap deserves attention since social capital may be more important for the physical welfare of people living in underdeveloped parts of the world. This is because the people in those regions are at an obvious disadvantage in terms of access to medical knowledge and services in stark contrast to those living in more privileged countries (Habibov \& Afandi, 2011; Kumar et al., 2012).

The limited number of studies focusing on non-North American and non-European context have produced inconsistent, and often conflicting, findings. Clearly, more evidence is needed to empirically test whether "the indicators of social capital developed in North America and Western Europe are valid in other cultural contexts" (Sapag et al., 2008, pp. 790).

\subsection{Literature Review}

\subsubsection{Cognitive and Structural Social Capital}

The present study seeks to contribute to the literature by analyzing a cross-national dataset on relatively understudied parts of the world when it comes to social capital and health, i.e., Asian countries. It focuses on two sets of social capital measures, one cognitive and another structure, as has been conventionally defined in the literature (Ferlander, 2007; Fujiwara \& Kawachi, 2008; Mansyur et al., 2008). The cognitive aspect of social capital refers to attitudes or subjective feelings. In the literature, trust has figured prominently in measuring this component. Specifically, scholars have looked at two different kinds of trust measures- generalized trust (i.e., "belief in strangers") and institutional or political trust (i.e., "confidence in the central government"), concepts that mainly derive from Putnam's (1993) work on social capital and civic participation. The structural or objective dimension of social capital, on the other hand, has to do with interpersonal relations and organizational memberships. In this particular research, the focus is on network relations with friends and relatives living abroad and ties with foreign friends living in the survey respondent's respective home country. In the past, most research conceptualized and measured the structural/interactional dimension of social capital by relying on network size or contact frequency strictly in terms of domestic ties. The current research incorporates into the analysis a new variable by considering how and to what extent having international connections may influence health outcomes.

\subsubsection{Trust and Subjective Health}

Many previous studies have investigated the empirical nexus between the two measures of trust and network size and subjective or self-rated health. For example, d'hombres, Rocco, Suhrcle, and McKee (2010) find a strong and positive relationship between trusting others and subjective health, while controlling for a host of socio-demographic and structural-level variables. In an oft-quoted piece, Fujiwara and Kawachi (2008) similarly report a significant association between social capital gauged in terms of trust in one's neighbors and lower rates of depression. A relationship between higher levels of interpersonal trust and lower psychological distress was also found in a study based on a population-wide survey of Australian adults (Phongsavan, Chey, Bauman, Brooks \& Silove, 2006). According to a large cross-national study covering 45 countries, generalized trust was found to have a robust and consistent effect on self-reported health (Mansyur et al., 2008). Poortinga (2006b) produce similar results in the European context: trusting individuals are more likely to report better health, ceteris paribus at both individual and contextual levels. In their research on rural China, Yip et al. (2007) report trust to have much more significant health benefits in comparison with organizational membership, a variable frequently used as an indicator of structural social capital. Concerning the effect of political or institutional trust, researchers have also found a similar significant association between this aspect of social capital and health outcomes (Baron-Epel, Weinstein, Blakely, Kennedy \& Kawachi, 2001; d'Hombres et al., 2010; Habibov \& 
Afandi, 2011; Yamaoka, 2008). The argument is that people who possess more political trust or those living in areas with greater institutional confidence at the community level are more likely to participate in civic engagement, be better informed about health-related issues, have better access to healthcare, and ultimately enjoy improved personal health (see e.g., Szreter \& Woolcock, 2004).

\subsubsection{Social Network and Physical Well-Being}

What is the evidence for the role of social network ties in promoting health outcomes? Scholars have used different ways to capture this structural component of social capital, which Kim and Kawachi (2006) refer to as "informal social interaction" that gauges the individual actors' levels of direct involvement in interpersonal relations. According to one study, social network diversity is intricately linked with heart disease and mortality. That is, people who interact more frequently with family and friends, but not neighbors or acquaintances, are less prone to experience negative health outcomes (Barefoot et al., 2005). Hooghe and Vanhoutte (2011) similarly discover that close interaction with family members leads to higher evaluation of subjective well-being. This empirical result is corroborated by Baron-Epel et al. (2008) who document the significant role of contact frequency with kin members and friends in promoting subjective health in the context of the Jewish and Arab communities in Israel. Based on a sample of urban residents in Moscow, Ferlander and Makinen (2009) investigate and confirm the relationship between the frequency of network contact and self-rated health. Based on a US representative sample, Cornwell and Waite (2009) produce additional evidence for the causal issue at hand: individuals who are socially disconnected are at a significant disadvantage in terms of mental health risks. Using a position generator to measure social capital, Song and Lin (2009) further show that access to network contacts in prestigious occupational categories significantly reduces depressive symptoms and boosts the overall perceive health status of individuals.

\subsubsection{Micro and Macro Conceptualizations of Social Capital}

In addition to the cognitive-structural split, social capital has been characterized along another important, and contested, conceptual dimension: individual ("micro") versus contextual ("macro"). The issue is whether social capital should be viewed as the attribute of individuals or something that is characteristic of a higher-level entity (e.g., neighborhood, community, society). Some have measured and analyzed social capital only at the individual level (e.g., Baron-Epel et al., 2008; Cornwell \& Waite, 2009; Yamaoka, 2008), some have examined it as an explicitly collective-level "neighborhood effect" (e.g., Aminzadeh, Denny, Utter, Milfont, Ameratunga, Teevale \& Clark, 2013; Browning \& Cagney, 2002; Mohnen et al., 2011), and others have taken a more integrative approach in investigating the possible interdependent or interactional effects of social capital across different levels (e.g., Kawachi et al., 2004; Phongsavan et al., 2006; Poortinga, 2006a, 2006b; Subramanian et al., 2002). Research attempts to overcome micro-macro dichotomy has led to greater reliance on multilevel modeling in simultaneously analyzing individual- and collective-level effects of social capital (Silva et al., 2005; Hooghe \& Vanhoutte, 2011; Kawachi et al., 2004; Phongsavan et al., 2006; Subramanian et al., 2002). In a similar vein, this study conceptualizes social capital at both individual and contextual levels. Taking this methodological approach is recommended since it can help avoid possible ecological and individualistic fallacies and tease out the potential confounding effects of social capital at different levels (see Poortinga, 2006b).

\subsection{Research Questions}

In light of the above discussion, six distinct but related lines of inquiries can be stated as follow, which guide the current research:

Q1. Conceptualized at the individual level, how and to what extent is generalized trust associated with subjective health among Asian populations?

Q2. Conceptualized at the individual level, how and to what extent is political trust associated with subjective health among Asian populations?

Q3. Conceptualized at the individual level, how and to what extent is social network associated with subjective health among Asian populations?

Q4. Conceptualized at the contextual (country) level, how and to what extent is generalized trust associated with subjective health among Asian populations?

Q5. Conceptualized at the contextual (country) level, how and to what extent is political trust associated with subjective health among Asian populations?

Q6. Conceptualized at the contextual (country) level, how and to what extent is social network associated with subjective health among Asian populations? 
The remainder of this research paper is devoted to answering the above research questions through empirical analysis. In the next section, the data, variables, and analytic methods used for the analysis are described, followed by the presentation of findings and interpretations. The last section concludes with the summary of results from the multilevel analysis and the limitations of this study and suggestions for future research.

\section{Method}

\subsection{Data Source}

Data examined in this study were collected by the Asian Barometer Project, which is headquartered in Taipei and co-hosted by the Institute of Political Science, Academia Sinica, and the Institute for the Advanced Studies of Humanities and Social Sciences at National Taiwan University. It was co-directed by Professors Fu Hu and Yun-han Chu and received major funding support from Taiwan's Ministry of Education, Academia Sinica, and National Taiwan University. The project is designed to collect cross-national information on the public opinion concerning political values, democracy, and governance in Asian countries. The regional network consists of national teams located in 13 East Asian (Japan, Mongolia, South Koreas, Taiwan, Hong Kong, China, the Philippines, Thailand, Vietnam, Cambodia, Singapore, Indonesia \& Malaysia) and 5 South Asian (India, Pakistan, Bangladesh, Sri Lanka \& Nepal) countries, whose primary goal is to compile data under a common research framework and methodology across different populations throughout Asia. The survey, using a multi-stage probability sampling method, was done through face-to-face personal interviewing, which lasted on average 60 minutes. Two waves of surveys have been conducted, the first one in 2003 and the second in 2006. The data examined in this research is the first wave of the Asian Barometer Survey (ABS) collected in 2003 containing representative samples from 10 countries: Japan, South Korea, China, Malaysia, Thailand, Vietnam, Myanmar, India, Sri Lanka, and Uzbekistan. Because of the politically sensitive nature of the question, the survey item about trusting in one's central government was not asked in Vietnam and Myanmar. Since this item is used in this research as one of the variables to measure social capital, these two countries are dropped from the analysis. Excluding missing cases, the resulting sample consists of 6,061 individuals from 8 countries.

\subsection{Outcome Variable}

The dependent variable is constructed based on the survey item that asks the respondents to rate various aspects of their lives, including health. The answer categories form a five-item Likert scale (e.g., 1 = "Very satisfied," 5 $=$ "Very dissatisfied"). They were first reverse-coded and then dichotomized so that the two answer choices "Very satisfied" and "Somewhat satisfied" are given the value of 1 and 0 otherwise ("Neither satisfied nor dissatisfied," "Somewhat dissatisfied," "Very dissatisfied"). The statistical models thus estimate the probability of belonging to "good" or "high" self-reported health category, which is consistent with the conventional coding and analytical scheme in the literature (e.g., d'Hombres et al., 2010; Moore et al., 2011; Sapag et al., 2007; Subramanian et al., 2002). Self-rated health has been commonly used in previous research and numerous longitudinal studies have confirmed it as a surrogate for more objective health measures (Poortinga, 2006a; Subramanian et al., 2001). In the sample, $67.4 \%$ (out of 6,061 ) belong to this health category.

\subsection{Social Capital Variables}

A number of indicators are created to gauge structural and cognitive social capital, three at the individual level and another three at the contextual level. The Asian Barometer Survey contains specific items about the respondent's network of relations with close contacts living abroad: "A member of my family or a relative lives in another country" and "friends who are from other countries." The affirmative response choice (i.e., "Apply") was assigned the value of 1 and 0 otherwise for both questions. At the individual level, the variable Social Network is created by summing up the answers, which ranges from 0 to 2 . The survey also inquired about the subjects' levels of generalized trust in two separate questions: "Generally, do you think people can be trusted or do you think that you can't be too careful in dealing with people, i.e., that it pays to be way of people?"; and "Do you think that people generally try to be helpful or do you think that they mostly look out for themselves?" Each affirmative answer to these questions was coded as 1. The variable General Trust thus also ranges from 0 to 2. As for the respondents' trust in their respective government, they were asked to "Please indicate to what extent you trust the following institutions to operate in the best interests of society." The answers were originally coded on a 4-point ordinal scale (e.g., $1=$ "Trust a lot," $4=$ "Don't trust at all"). Reverse-coding was done to reflect a higher score for greater institutional trust for the variable Political Trust, which ranges from 1 to 4 . To capture social capital indicators at the contextual level, it is customary in the literature to aggregate responses given at the individual level across the higher level (in this study, countries) and then to calculate the average scores. Doing so creates three additional measures: C_Social Network, C_General Trust, C_Political Trust, with the mean values of $1.70,0.63$, and 2.72 , respectively. These numbers thus reflect the national average score for each 
of the three social capital categories.

\subsection{Control Variables}

To offer a conservative test of the multilevel effects of social capital on health, a number of background variables are taken into consideration, such as age (measured in years), gender ("male" =1), marital status ("married" = 1), and education, an ordinal variable based on a 6-point scale $(1=$ "No formal education," $6=$ "University/graduate school). As another indicator of human capital, the respondent's English foreign language ability is measured. The values for the variable English ("How well do you speak English?") range from 4 ("fluently") to 1 ("not at all"). The variable Subjective Class ("How would you describe your standard of living?") is measured on a 5-point ordinal scale (5 = "High," 1 = "Low"). And individual religious background is also controlled for. Among the five dummy categories (Catholic, Protestant, Buddhist, Hindu, Muslim, "Other"), Muslim is the omitted baseline group. Lastly, the respondents' engagement with voluntary organizations or civic participation (measured as Civic Life) is included. The Asian Barometer Survey unfortunately does not ask directly about the membership size or level of participation. Instead, the survey contains the following question: "Which of the following social circles or groups are important to you?" The respondents were given a list of subjects (family, work, religion, club/hobbies, etc.) to state whether or not they consider them "important." In the extant literature, along with the network size and contact frequency, voluntary association or organizational participation is one of the most frequently used indicators of structural social capital. In this research, given the data limitation, this item is included in the analysis as a (dummy) control variable.

\subsection{Analytic Method}

Since the Asian Barometer Survey has a nested data structure where individual respondents are clustered within different countries, hierarchical linear modeling (Raudenbush \& Bryk, 2002) is used to examine the causal link between various measures of social capital (generalized trust, political trust, social network) and the outcome variable (self-rated health). Two-level random-coefficient logistic regression models are fitted using the maximum likelihood estimation, in order to distinguish associations between individual - and contextual-level social capital and subjective health. The basic model is represented by the following equation:

$$
H_{i j}=\beta_{0}+\beta_{l}\left(S_{i j}-S_{k}\right)+\beta_{2} S_{j}+\beta_{3} \boldsymbol{X}_{i j}+\mu_{j}+\varepsilon_{i j} \text {, }
$$

where $H$ is the subjective health outcome for individual $i$ in country $j, S$ is the set of social capital variables measured at the individual (level 1) and country (level 2) levels, $\boldsymbol{X}$ is a vector of control variables (age, gender, marital status, educational level, English ability, subjective class status, civic life, religious background). The $\beta$ 's are "fixed" parameters to be estimated, $\mu_{j}$ is the country-specific random effect, and $\varepsilon_{i j}$ is the random component of the error term. To address the problem of collinearity, the level-1 social capital variables are centered at the group mean, as indicated by the term $\left(S_{i j}-S_{k}\right)$, i.e., calculated as the mean value of the individual responses in the designated country. All statistical analyses were performed using HLM 7 (Raudenbush, Bryk \& Congdon, 2010). 
Table 1. Descriptive statistics

\begin{tabular}{|c|c|c|c|c|c|}
\hline Variables & $\mathrm{N}$ & Mean & Std. Dev. & Min & Max \\
\hline \multicolumn{6}{|l|}{ (Level 1) } \\
\hline Health Status & 6061 & 0.67 & 0.45 & 0 & 1 \\
\hline Male & 6061 & 0.50 & 0.50 & 0 & 1 \\
\hline Married & 6061 & 0.71 & 0.45 & 0 & 1 \\
\hline Age & 6061 & 37.33 & 11.03 & 20 & 59 \\
\hline Education & 6061 & 3.86 & 1.47 & 1 & 6 \\
\hline English & 6061 & 1.96 & 0.91 & 1 & 4 \\
\hline Subjective Class & 6061 & 3.00 & 0.74 & 1 & 5 \\
\hline Civic Life & 6061 & 0.12 & 0.33 & 0 & 1 \\
\hline Social Network & 6061 & 1.71 & 0.49 & 0 & 2 \\
\hline Catholic & 6061 & 0.03 & 0.16 & 0 & 1 \\
\hline Protestant & 6061 & 0.06 & 0.24 & 0 & 1 \\
\hline Hindu & 6061 & 0.14 & 0.35 & 0 & 1 \\
\hline Buddhist & 6061 & 0.30 & 0.46 & 0 & 1 \\
\hline Political Trust & 6061 & 2.74 & 0.94 & 1 & 4 \\
\hline General Trust & 6061 & 0.63 & 0.75 & 0 & 2 \\
\hline \multicolumn{6}{|l|}{ (Level 2) } \\
\hline C_General Trust & 8 & 0.63 & 0.26 & 0.30 & 1.07 \\
\hline C_Social Network & 8 & 1.70 & 0.12 & 1.51 & 1.83 \\
\hline C_Political Trust & 8 & 2.72 & 0.56 & 1.96 & 3.39 \\
\hline
\end{tabular}

Source: Asian barometer survey (2003)

\section{Results}

\subsection{Null Model}

Table 1 contains descriptive statistics for the variables used in the multilevel analysis. Table 2 consists of different regression models that are estimated. Model 1 is the null (intercept-only) model. Based on the output from this model, the intercept component is found to be significant $(\mathrm{p}<.0001)$, indicating that the level-2 (country-level) variance makes an independent contribution in explaining the outcome variable (self-rated health). This also means that running ordinary least squares models would suffer from correlated error and that some form of linear mixed modeling is required (Snijiders \& Boskers, 1999). The intraclass correlation coefficient (ICC) is calculated as .086. In other words, the proportion of variance in subjective health explained by the level-1 variance component is 91.4 percent and that explained by the level-2 variance component (i.e., country-level differences) is 8.6 percent.

\subsection{Model 2 (Controls Only) and Model 3 (Level-1 Social Capital Variables \& Controls)}

Model 2 is the model with the control variables only. Only two of them reach the level of significance: age and subjective class status. Not surprisingly, as the minus sign of the coefficient suggests, older people are less likely to report to be in good health $(\mathrm{p}<.001)$, and people who view themselves as belonging to a higher socioeconomic group are more likely to say that they are happier with their health $(\mathrm{p}<.0001)$. Model 3 
introduces the three individual-level social capital indicators: Social Network, General Trust, and Political Trust. According to the output, while controlling for a host of socioeconomic and demographic variables, all three are significantly associated with subjective health. Individuals who have family members and relatives living abroad and/or have foreign friends in their own country are more likely to report better health $(\mathrm{p}<.05)$. People who are more willing to trust others have a higher probability of stating that they are happier with their own health status as well $(\mathrm{p}<.05)$. Lastly, those who place greater institutional confidence in their government are more likely to score higher on the subjective health evaluation $(\mathrm{p}<.05)$. The two control variables (age and subjective class) remain statistically significant in this model.

\subsection{Model 4 (Level-2 Social Capital Variables \& Controls)}

Model 4 consists of the parameter estimates for the level-2 (country-level) social capital variables along with the socio-demographic controls, while excluding the individual-level social capital indicators. Again, age and subjective class are found to be significant. As the findings indicate, all three aggregate measures of social capital (C_General Trust, C_Political Trust, C_Social Network) reach the level of statistical significance. On average, people who live in a country with compatriots who score higher on the social network scale have a greater probability of reporting better health $(p<.0001)$. There is also a greater chance of those who live in countries with higher national levels of both general trust and political trust to be more satisfied with their own health status $(\mathrm{p}<.05)$.

\subsection{Model 5 (Full Model)}

Model 5 is the full model that incorporates all six social capital indicators at individual and country levels. As the three individual-level social capital variables are reintroduced into this model, two of the variables measured at the country level become statistically insignificant, namely C_General Trust and C_Political Trust. The one that retains its significance is $C$ _Social Network $(\mathrm{p}<.05)$, which indicates that higher average health perception is associated with living in a country with a relatively high national level of network relations with foreign friends and having kin ties abroad. This finding is consistent with some of the earlier research, including the one based on a representative US population, where the neighborhood-level contextual effect of social capital loses its significance after controlling for individual trust perception (Subramanian et al., 2002). The results also complement another study in which the inclusion of individual-level interpersonal trust diminishes the significance of collective-level social capital measures, i.e., aggregate civic participation and aggregate social trust, though more complex cross-level interaction effects are detected (Poortinga, 2006a). Concerning the level-1 social capital indicators, the effects for all three remain robust: individuals with larger network size, higher generalized trust, and greater institutional confidence have a greater probability to report themselves as being healthier $(\mathrm{p}<.05)$.

\subsection{Random Component}

In addition to the fixed effects as discussed, the random effects from the multilevel models also provide information about social capital as a contextual (country-level) phenomenon. The idea of contextual effect is intricately tied to the statistical notion of clustering (Merlo, Chaix, Yang, Lynch \& Rastam, 2005). If the health statuses of individuals are more similar within rather than across countries, for example, there is a greater probability that the determinants of health are to be found within the contextual environment. As mentioned earlier, according to the ICC calculation from the null model, $8.6 \%$ of the overall variance in the outcome variable is found at the country level. This clustering of self-rated health at the higher level, however, becomes non-significant in Model 4 and Model 5, when aggregate social capital indicators are included in the analysis. Clustering is thus more than just a statistical problem that must be addressed in producing correct model estimations. As a key concept, it also reveals relevant information by itself about explained variances (Poortinga, 2006b). 
Table 2. Fixed and random parameter estimates from the multilevel analysis of health

\begin{tabular}{|c|c|c|c|c|c|}
\hline Variables & Model 1 & Model 2 & Model 3 & Model 4 & Model 5 \\
\hline Constant & & $0.719(0.047)^{* * *}$ & $0.719(0.047)^{* * *}$ & $0.719(0.055)^{* * *}$ & $0.719(0.034)^{* * *}$ \\
\hline \multicolumn{6}{|l|}{ Level-1 (Individual) } \\
\hline Male & & $0.031(0.026)$ & $0.032(0.026)$ & $0.032(0.026)$ & $0.032(0.026)$ \\
\hline Married & & $0.025(0.023)$ & $0.020(0.023)$ & $0.024(0.022)$ & $0.020(0.023)$ \\
\hline Age & & $-0.005(0.001)^{* *}$ & $-0.005(0.001)^{* *}$ & $-0.005(0.001)^{* *}$ & $-0.005(0.001)^{* *}$ \\
\hline Education & & $-0.012(0.008)$ & $-0.011(0.008)$ & $-0.012(0.008)$ & $-0.011(0.008)$ \\
\hline English & & $-0.011(0.009)$ & $0.013(0.009)$ & $0.010(0.009)$ & $0.013(0.009)$ \\
\hline Subjective Class & & $0.105(0.017)^{* * *}$ & $0.095(0.018)^{* * *}$ & $0.105(0.018)^{* * *}$ & $0.095(0.018)^{* * *}$ \\
\hline Civic Life & & $-0.036(0.019)$ & $-0.038(0.019)$ & $-0.034(0.019)$ & $-0.037(0.019)$ \\
\hline Catholic & & $-0.006(0.056)$ & $0.027(0.065)$ & $0.004(0.051)$ & $0.026(0.062)$ \\
\hline Protestant & & $0.088(0.065)$ & $0.088(0.059)$ & $0.070(0.048)$ & $0.092(0.054)$ \\
\hline Hindu & & $-0.052(0.040)$ & $-0.055(0.044)$ & $-0.18(0.039)$ & $-0.043(0.043)$ \\
\hline Buddhist & & $0.043(0.031)$ & $0.050(0.030)$ & $0.043(0.030)$ & $0.051(0.030)$ \\
\hline Social Network & & & $0.043(0.016)^{*}$ & & $0.042(0.017)^{*}$ \\
\hline General Trust & & & $0.038(0.013)^{*}$ & & $0.038(0.013)^{*}$ \\
\hline Political Trust & & & $0.031(0.011)^{*}$ & & $0.032(0.011)^{*}$ \\
\hline \multicolumn{6}{|l|}{ Level-2 (Country) } \\
\hline C_General Trust & & & & $0.479(0.144)^{*}$ & $0.219(0.098)$ \\
\hline C_Social Network & & & & $3.198(0.486)^{* * *}$ & $1.483(0.326)^{*}$ \\
\hline C_Political Trust & & & & $-0.026(0.085)^{*}$ & $-0.076(0.057)$ \\
\hline \multicolumn{6}{|l|}{ Variance Components } \\
\hline Level 1 (Individual) & .1857 & .1736 & .1707 & .1737 & .1708 \\
\hline Level 2 (Country) & .0176 & .0175 & .0175 & .0239 & .0091 \\
\hline ICC & 8.66 & 9.16 & 9.33 & 12.09 & 5.01 \\
\hline$-2 \mathrm{LL}$ & 7117.71 & 6731.01 & 6663.42 & 6738.01 & 6667.01 \\
\hline
\end{tabular}

Source: Asian barometer survey (2003)

Note: $*<.05, * *<.01, * * *<.001 ;$ Standard errors are in parentheses.

\section{Discussion}

\subsection{Summary of Findings}

There has been much controversy over the conceptualization and measurement of social capital in estimating its effects on psychological well-being and physical health. The social capital research on public health has produced two separate but related findings. One the one hand, social capital has been viewed by some scholars as an attribute of individual actors, while others have insisted on seeing it as a property of higher-level entities such as communities, neighborhoods or even societies. Based on the hierarchical linear modeling of the Asian Barometer Survey (2003) dataset, the current research set out to contribute to the extant literature by examining the possible association between self-rated health and social capital conceptualized and measured at both individual and contextual levels. A number of significant findings emerge from the analysis. First of all, there are two consistent and robust effects of socioeconomic-demographic variables, namely age and subjective class, on people's self-perception of health. In the context of Asian countries, ceteris paribus, younger people and those occupying higher class positions are more likely to view themselves to be in better health.

This finding is robust across different models and is largely consistent with what has been reported in previous research on Europe and North America. None of the other control variables, however, is significantly associated 
with the degree to which people evaluate their health. There is no gender or marital difference. Human capital variables (Education \& foreign language ability) fail to have an effect. Nor does religious background or valuing organizational participation make any difference. Concerning the main focus of this research centered on the linkage between social capital and subjective health, some, but not all, individual- and contextual-level effects are found to be significant. To summarize, there are three specific lessons from this study. First, at the individual level, trusting people (in others as well as in their government) report better health. Second, those who have wider international network of friends and kin members also give higher self-evaluation. At higher average values of the social network measure at the national level are associated with higher self-rated health scores at the individual level.

These new findings lend further evidence to the social science research on the potential health benefits of cognitive and structural social capital. More specifically, they reveal that social capital cannot be understood exclusively as an "individual" or "collective" phenomenon. Rather, it is something that belongs to both domains and that a multilevel method of analysis is required to simultaneously investigate how and to what extent social capital is related to subjective health. This study also extends the existing literature by turning the analytical focus on a group of Asian countries, which has not received a great deal of scholarly attention. Some researchers in a limited number of studies have explored the association between social capital and health in various parts of developing and transitional societies including, for example, rural China (Yip et al., 2007), a low income community in Chile (Sapag et al., 2008), Hungary (Skrabski, Kopp \& Kawachi, 2004), Russia (Ferlander \& Makinen, 2009; Rojas \& Carlson, 2006), the Middle East (Baron-Epel et al., 2008), the Commonwealth of Independent States (d'Hombres et al., 2010), and the South Caucasus region (Habibov \& Afandi, 2011). Based on the analysis of the Asian Barometer Survey, the current research adds to these and other related studies in testing the validity of the social capital argument outside the context of economically more developed Western liberal democracies.

\subsection{Limitations and Future Direction}

This study has some limitations. Perhaps the most notable shortcoming is the cross-sectional nature of the analyzed data, a seemingly universal problem that pervades the social capital research on public health. As has been pointed out in the past, the examination of cross-sectional data does not offer conclusive evidence on causality. In fact, "reverse causality cannot be ruled out" (Subramanian et al., 2002), especially concerning the effects of cognitive social capital on health outcomes. That is, for example, people who are healthier may be more willing and likely to trust others and/or place greater trust in the institutional political authority. Longitudinal data are thus needed to establish a more definitive causal relationship between the exogenous and endogenous variables. Another methodological issue is that in the current study the indicators of social capital were relatively limited: that is, it was measured strictly in terms of generalized trust, political trust, and social network. In previous research, other concepts like collective efficacy, contact frequency and organizational membership have been applied to gauge social capital. Unfortunately, the Asian Barometer Survey does not contain details on how often the subjects interact with their network contacts or the level of interpersonal trust they have in their neighbors or community members in upholding shared values, working together toward a common goal, etc. Nor does the survey inquire specifically about the level of participation in voluntary associations other than simply asking how important the respondents consider it to be in their personal lives. The data limitation thus precluded conceptualizing and measuring social capital in a more comprehensive fashion. The results of this study need to be interpreted with some caution as well given the relatively small number of level-2 categories $(\mathrm{N})$, i.e., the number of countries in which the individual respondents are nested. A larger dataset containing sample populations from more countries would be necessary to offer more accurate model estimations and better generalizations across the area under investigation. Future research should address the limitations mentioned above in presenting new empirical findings to gain a better understanding of the dynamics underlying "social determinants of health."

\section{References}

Barefoot, J., Gronbaek, M., Jensen, G., Schnohr, P., \& Prescott, E. (2005). Social Network Diversity and Risks of Ischemic Heart Disease and Total Mortality: Findings from the Copenhagen City Heart Study. American Journal of Epidemiology, 161, 960-967. http://dx.doi.org/10.1093/aje/kwi128

Baron-Epel, O., Weinstein, R., Haviv-Mesika, A., Garty-Sandalon, N., \& Green, S. (2008). Individual-level analysis of social capital and health: A comparison of Arab and Jewish Israelis. Social Science \& Medicine, 66, 900-910. http://dx.doi.org/10.1016/j.socscimed.2007.10.025

Berkman, L. F., Glass, T., Brissette, I., \& Seeman, T. E. (2000). From social integration to health: Durkheim in 
the new millennium. Social Science \& Medicine, 51, 843-847. http://dx.doi.org/10.1016/S0277-9536(00)00065-4

Bourdieu, P. (1986). The forms of capital. In J. Richardson (Ed.), Handbook of Theory and Research for the Sociology of Education (New York, Greenwood), 241-258.

Browning, C. R., \& Cagney, K. A. (2002). Neighborhood Structural Disadvantage, Collective Efficacy, and Self-Rated Physical health in an Urban Setting. Journal of Health and Social Behavior, 43, 383-399. http://dx.doi.org/10.2307/3090233

Coleman, J. S. (1988). Social capital in the creation of human capital. American Journal of Sociology, 94, 95-120. http://dx.doi.org/10.1086/228943

d'Hombres, B., Rocco, L., Suhrcke, M., \& McKee, M. (2010). Does Social Capital Determine Health? Evidence From Eight Transition Countries. Health Economics, 19, 56-74.

Durkheim, E. (1951). Suicide: A study in sociology. New York: Free Press.

Ferlander, S. (2007). The Importance of different forms of social capital for health. Acta Sociologica, 50, 115-128. http://dx.doi.org/10.1177/0001699307077654

Ferlander, S., \& Makinen, I. H. (2009). Social capital, gender and self-rated health. Evidence from the Moscow Health Survey 2004. Social Science and Medicine, 69, 1323-1332. http://dx.doi.org/10.1016/j.socscimed.2009.08.009

Fujiwara, T., \& Kawachi, I. (2008). A prospective study of individual-level social capital and major depression in the United States. Journal of Epidemiology \& Community Health, 62, 627-633. http://dx.doi.org/10.1136/jech.2007.064261

Habibov, N., \& Afandi, E. (2011). Self-rated health and social capital in transitional countries: Multilevel analysis of comparative surveys in Armenia, Azerbaijan, and Georgia. Social Science \& Medicine, 72, 1193-1204. http://dx.doi.org/10.1016/j.socscimed.2011.01.035

Hooghe, M., \& Vanhoutte, B. (2011). Subjective Well-Being and Social Capital in Belgian Communities. The Impact of Community Characteristics on Subjective Well-Being Indicators in Belgium. Social Indicators Research, 100, 17-36. http://dx.doi.org/10.1007/s11205-010-9600-0

Kawachi, I., \& Berkman, L. F. (2000). Social cohesion, social capital, and health. In L. F. Berkman \& I. Kawachi (Eds.), Social Epidemiology (pp. 174-190). New York: Oxford University Press.

Kawachi, I., Kennedy, B. P., Lochner, K., \& Prothrow-Stith, D. (1997). Social capital, income inequality, and mortality. American Journal of Public Health, 87, 1491-1498. http://dx.doi.org/10.2105/AJPH.87.9.1491

Kawachi, I., Kim, D., Coutts, A., \& Subramanian, S. V. (2004). Commentary: Reconciling the three accounts of social capital. International Epidemiological Association, 33, 682-690. http://dx.doi.org/10.1093/ije/dyh177

Kim, D., \& Kawachi, I. (2006). A Multilevel Analysis of Key Forms of Community- and Individual-Level Social Capital as Predictors of Self-Rated Health in the United States. Journal of Urban Health: Bulletin of the New York Academy of Medicine, 83, 813-826.

Kim, D., Subramanian, S. V., \& Kawachi, I. (2006). Bonding versus bridging social capital and their associations with self-rated health: a multilevel analysis of 40 U.S. communities. Journal of Epidemiology \& Community Health, 60, 116-122. http://dx.doi.org/10.1136/jech.2005.038281

Kumar, S., Calvo, R., Avendano, M., Sivaramakrishnan, K., \& Berkman, L. F. (2012). Social support, volunteering and health around the world: cross-national evidence from 139 countries. Social Science \& Medicine, 74, 696-706. http://dx.doi.org/10.1016/j.socscimed.2011.11.017

Mansyur, C., Amick, B., Harrist, R., \& Franzini, L. (2008). Social capital, income inequality, and self-rated health in 45 countries. Social Science \& Medicine, 66, 43-56. http://dx.doi.org/10.1016/j.socscimed.2007.08.015

Mohnen, S., Groenewegen, P., Volker, B., \& Flap, H. (2011). Neighborhood social capital and individual health. Social Science \& Medicine, 72, 660-667. http://dx.doi.org/10.1016/j.socscimed.2010.12.004

Moore, S., Bockenholt, U., Daniel, M., Frohlich, K., Kestens, Y., \& Richard, L. (2011). Social capital and core network ties: A validation study of individual-level social capital measures and their association with extraand intra- neighborhood ties, and self-rated health. Health \& Place, 17, 536-544. http://dx.doi.org/10.1016/j.healthplace.2010.12.010 
Phongsavan, P., Chey, T., Bauman, A., Brooks, R., \& Silove, D. (2006). Social capital, socio-economic status and psychological distress among Australian adults. Social Science \& Medicine, 63, 2546-2561. http://dx.doi.org/10.1016/j.socscimed.2006.06.021

Poortinga, W. (2006a). Social capital: an individual or collective resource for health? Social Science \& Medicine, 62, 292-302. http://dx.doi.org/10.1016/j.socscimed.2005.06.008

Poortinga, W. (2006b). Social relations or social capital? Individual and community health effects of bonding social capital. Social Science \& Medicine, 63, 255-270. http://dx.doi.org/10.1016/j.socscimed.2005.11.039

Putnam, R. D. (1993). Making democracy work: Civic traditions in modern Italy. Princeton, NJ: Princeton University Press.

Raudenbush, S. W., \& Bryk, A. S. (2002). Hierarchical linear models: Applications and data analysis methods. Thousand Oaks, CA: Sage Publications.

Raudenbush, S. W., Bryk, A. S., \& Congdon, R. (2010). HLM 7: Hierarchical linear and nonlinear modeling. Lincolnwood, IL: Scientific Software International.

Rojas, Y., \& Carlson, P. (2006). The stratification of social capital and its consequences for self-rated health in Taganrog, Russia. Social Science \& $\quad$ Medicine, 62(11), 2732-2741. http://dx.doi.org/10.1016/j.socscimed.2005.11.007

Sapag, J. C., Aracena, M., Villarroel, L., Poblete, F., Berrocal, C., Hoyos, R., Martinez, M., \& Kawachi, I. (2008). Social capital and self-rated health ain urban low income neighbourhoods in Chile. Journal of Epidemiology \& Community Health, 62, 790-792. http://dx.doi.org/10.1136/jech.2006.052993

Silva, M. J., McKenzie, K., Harpham, T., \& Huttly, S. (2005). Social capital and mental illness: a systematic review. Journal of Epidemiology \& Community Health, 59, 619-627. http://dx.doi.org/10.1136/jech.2004.029678

Skrabski, A., Kopp, M., \& Kawachi, I. (2004). Social Capital and Collective Efficacy in Hungary: Cross Sectional Associations with Middle Aged Female and Male Mortality Rates. Journal of Epidemiology \& Community Health, 58, 340-345. http://dx.doi.org/10.1136/jech.2003.010017

Smith, K. P., \& Christakis, N. A. (2008). Social Networks and Health. Annual Review of Sociology, 34, $405-429$. http://dx.doi.org/10.1146/annurev.soc.34.040507.134601

Snijders, T. A. B., \& Bosker, R., J. (1999). Multilevel analysis: An introduction to basic and advanced multilevel modeling. London: Sage.

Song, L., \& Lin, N. (2009). Social Capital and Health Inequality: Evidence from Taiwan. Journal of Health and Social behavior, 50, 149-163. http://dx.doi.org/10.1177/002214650905000203

Subramanian, S. V., Kim, D. J., \& Kawachi, I. (2002). Social Trust and Self-Rated Health in US Communities: a Multilevel Analysis. Journal of Urban Health: Bulletin of the New York Academy of Medicine, 79, S21-S34.

Szreter, S., \& Woolcock, M. (2004). Health by association? Social capital, social theory, and the political economy of public health. International Journal of Epidemiology, 33, 650-667. http://dx.doi.org/10.1093/ije/dyh013

Uchino, B. (2006). Social Support and Health: A Review of Physiological Processes Potentially Underlying Links to Disease Outcomes. Journal of Behavioral Medicine, 29, 377-388. http://dx.doi.org/10.1007/s10865-006-9056-5

Yamaoka, K. (2008). Social capital and health and well-being in East Asia: A population-based study. Social Science \& Medicine, 66, 885-899. http://dx.doi.org/10.1016/j.socscimed.2007.10.024

Yip, W., Subramanian, S. V., Mitchell, A. D., Lee, T. S., Wang, J., \& Kawachi, I. (2007). Does social capital enhance health and well-being? Evidence from rural China. Social Science \& Medicine, 64, 35-49. http://dx.doi.org/10.1016/j.socscimed.2006.08.027

\section{Copyrights}

Copyright for this article is retained by the author(s), with first publication rights granted to the journal.

This is an open-access article distributed under the terms and conditions of the Creative Commons Attribution license (http://creativecommons.org/licenses/by/3.0/). 